\title{
QUEEN'S
UNIVERSITY
BELFAST
}

\section{Efficacy of a powered wheelchair simulator for school aged children: A randomised controlled trial.}

Linden, M. A., Whyatt, C., Craig, C., \& Kerr, C. (2013). Efficacy of a powered wheelchair simulator for school aged children: A randomised controlled trial. Rehabilitation Psychology, 58(4), 405-411.

https://doi.org/10.1037/a0034088

\section{Published in:}

Rehabilitation Psychology

\section{Document Version:}

Peer reviewed version

Queen's University Belfast - Research Portal:

Link to publication record in Queen's University Belfast Research Portal

\section{Publisher rights}

Copyright 2013 American Psychological Association (APA)

This article may not exactly replicate the final version published in the APA journal. It is not the copy of record.

\section{General rights}

Copyright for the publications made accessible via the Queen's University Belfast Research Portal is retained by the author(s) and / or other copyright owners and it is a condition of accessing these publications that users recognise and abide by the legal requirements associated with these rights.

Take down policy

The Research Portal is Queen's institutional repository that provides access to Queen's research output. Every effort has been made to ensure that content in the Research Portal does not infringe any person's rights, or applicable UK laws. If you discover content in the Research Portal that you believe breaches copyright or violates any law, please contact openaccess@qub.ac.uk. 
RUNNING HEAD: EFFICACY OF A POWERED WHEELCHAIR SIMULATOR

Rehabilitation Psychology 2013, 58(4)405-411. DOI: 10.1037/a0034088

Efficacy of a powered wheelchair simulator for school aged children: A randomised controlled trial.

Mark A. Linden ${ }^{1} \mathrm{PhD}$, Caroline Whyatt ${ }^{2} \mathrm{PhD}$, Cathy Craig ${ }^{2} \mathrm{PhD}$, Claire Kerr ${ }^{1} \mathrm{PhD}$.

1. School of Nursing \& Midwifery, The Queen's University of Belfast, United Kingdom. 2.

School of Psychology, The Queen's University of Belfast, United Kingdom.

Corresponding author: Dr Mark Linden

School of Nursing \& Midwifery

The Queen's University of Belfast,

97 Lisburn Road

Belfast,

BT9 7BL

Northern Ireland

e-mail:m.linden@qub.ac.uk

Phone: +44 (0)28 90972820

Fax: + 44 (0)2890972328

\section{Abstract}

Purpose: To determine the efficacy of a custom made wheelchair simulation in training children to use a powered wheelchair (PWC). Design: Randomised controlled trial employing 
the 4C/ID-model of learning. Twenty-eight typically developing children (13M, 15F; mean age 6 years, SD 6 months) were assessed on their operation of a PWC using a functional evaluation rating scale. Participants were randomly assigned to intervention (8x 30minute training sessions using a joystick operated wheelchair simulation) or control conditions (no task), and were re-assessed on their PWC use following the intervention phase. Additional data from the simulation on completion times, errors and total scores were recorded for the intervention group. Results: Analysis of variance showed a main effect of time, with planned comparisons revealing a statistically significant change in PWC use for the intervention $(p=0.022)$ but not the control condition. Whilst the intervention group showed greater improvement than the controls this did not reach statistical significance. Multiple regression analyses showed that gender was predictive of pre-test $(p=0.005)$ functional ability. Implications: A simulated wheelchair task appears to be effective in helping children learn to operate a PWC. Greater attention should be given to female learners who underperformed when compared to their male counterparts. This low cost intervention could be easily employed at home to reduce PWC training times in children with motor disorders.

Keywords: Computer simulation, powered wheelchair, children, randomised controlled trial

\section{Impact}

- This feasibility study is the first to design and test a PWC simulator, based on an established theoretical model, which is low cost and potentially suitable for home use

- This research suggests that a computer based wheelchair simulation can improve training in the operation of a PWC in school-aged children

- Additional research is needed to explore the effectiveness of the PWC simulation in a clinical sample of childhood wheelchair users 
The ability to move is central to our survival and has played a crucial role in our evolutionary past. Movement allows us to interact with our environment, locate resources, learn about the world and interact with others. A child's cognitive and psychosocial development is therefore affected by their ability to move (Fernandes, 2006; Home, \& Ham 2003). The World Health Organisation has recognised that children who experience reduced mobility are at increased risk of being denied educational opportunities, with the resulting impact on future employment and poverty (Armstrong et al., 2008).

Estimates of the number of wheelchair users vary across regions and range from $1-2 \%$ of the population (DHSSPSNI, 2008). Figures from the UK suggest approximately 1.2 million wheelchair users (Sedgwick, Frank, Kemp, \& Gage, 2005) while those from the US suggest 2.7 million $>15$ years and $121,000<15$ years (Steinmetz, 2004). However a recent report published by the All Party Parliamentary Group for Paediatric Wheelchair Reform reported that many children in the UK were denied PWC due to local eligibility criteria, typically the child's age (Whizz-Kidz, 2011), instead of addressing the individual's clinical, developmental, educational and social needs (Sharma \& Morrison, 2007). Environmental constraints such as financial resources, size of family homes, space in public facilities and ease of transportation have also been cited as barriers to the provision of PWC for children with cerebral palsy (Palisano et al., 2003).

The importance of movement in a child's development suggests that the provision of assistive devices (e.g. scooters, powered wheelchairs, walking frames) should take place at an early age (Magnuson, 1996). Children as young as 20 months have been shown to benefit from powered mobility (Jones, McEwen, \& Hansen, 2003). Researchers have demonstrated that driving competency can be achieved by early provision (ages 3-8 years) of a powered 
wheelchair (PWC) in children with cerebral palsy, irrespective of intellectual impairment (Bottos, Bolcati, Sciuto, Ruggeri, \& Feliciangeli, 2001). Others have demonstrated improvements in communication, social, and cognitive skills in a child with spinal muscular atrophy (Jones et al., 2003). Given the benefits it would seem advantageous to begin training with these devices as soon as the child is able. Typically this training occurs in a real-world environment, and is often labour-intensive, frequently requiring the supervision and/or assistance of rehabilitation professionals. Furthermore, training is not always delivered in a consistent fashion with some children receiving no training in the operation of their PWC (Home \& Ham, 2003). The development of low cost, effective and engaging training tools could address the gap in training provision and reduce the time and costs associated with learning this complex skill.

Powered wheelchairs and other assistive devices, allow the child to independently move within their physical environments. However, the impact of such a device on the social environment will highlight that this child is different from their peer group. Such outward markers of difference can create expectations of behaviour which are inconsistent with the goals of the child (Linden \& McClure, 2012). The subversion of such expectations can lead to negative peer attitudes and discrimination (Crothers, Linden \& Kennedy, 2007). Alternatively, these markers can serve to convey information about the child's deficit which can lead to additional support and understanding (Brooks 1991). A study exploring the experiences of childhood users of assistive devices suggests that children view such devices in a positive light, based on their utility to increase participation in school life (Huang, Sugden, \& Beveridge, 2009). Whilst children are aware that the use of such devices identifies them as being different, the benefits they receive are seen to outweigh the negatives (Huang et al., 2009). The authors highlight the importance of a supportive school environment which 
accepts the use of devices, enabling their practice, and allowing the children to feel accepted by both teachers and peers. This is important as childhood users of wheelchairs may face a lowering of expectations to achieve academic success and gain future employment (Sapey, Stewart, \& Donaldson, 2004). The provision and training of wheelchair use supports participation and inclusion in educational and social activities, in line with the UN convention on the Rights of the Child (Davies, 2006).

The learning of complex tasks (e.g. operating a PWC) has been explained using the four components of instructional design (4C/ID) model (van Merriënboer, Jelsma, \& Paas, 1992). The model describes four interrelated components; Learning tasks are regarded as instructional methods which enable an individual to construct schemata based on concrete experiences which are innate to the learning task; Supportive information provides a framework on which individuals build on their prior experience to establish associations between what is already known and the new elements of the task; Just-In-Time (JIT) information provides the learner with a series of rules to follow in order to complete the task; The Part-task Practice component of the model describes training to promote automaticity of the rules and skills to accomplish the task (van Merriënboer, Clark, \& de Croock, 2002).

There are few available studies which explore the use of simulation in childhood users of PWCs. Virtual reality (VR) has been employed by researchers to explore the use of PWCs in children with severe orthopaedic injuries (Inman, Loge, Cram, \& Peterson, 2011). Inman et al (2011) used a training platform which allowed the child's wheelchair to move and relayed information to the virtual environment to produce simulated movement. Thirteen children, $93 \%$ of whom had cerebral palsy (mean age 11 years), took part in the study and showed improved driving skills on completion. Hasdai, Jesse, and Weiss (1998) developed a 
simulated PWC maze task for children (mean age 13.6 years) with progressive muscular dystrophy and cerebral palsy. Children were required to guide a cursor from its start to an end position without colliding with walls or barriers. Inexperienced wheelchair users significantly improved their real world PWC driving performance following a period of training on Hasdai et al's (1998) task. The use of specialised equipment such as the training platform in Inman et al's (2011) work would largely preclude the widespread home use of this simulator. Use of the VR environment itself may prove beneficial however no data were available on its effectiveness. The basic 2-dimensioinal VR environment of Hasdai et al (1998), whilst effective, lacks the sophistication that most contemporary computer literate children would expect from a simulation.

The current project describes a feasibility study undertaken to develop and evaluate the effects of a PWC simulation on learning to operate a PWC. Unlike previous research this work utilised a piece of software that could be used on any home PC, making the intervention both easily accessible and cost-effective. Developed around the framework of the 4C/IDmodel, this simulation provided school children with a concrete task to achieve, built on a familiar gaming environment which contained a predetermined set of rules, and allowed for repetition to facilitate learning. The thesis of the study was that the simulation would be sufficiently accurate to produce a transferred learning effect in the operation of a PWC.

\section{Method}

\section{Ethical approval}

Ethical approval was granted for the study by a University based research ethics committee. All parents provided written informed consent, and children provided verbal assent prior to testing and training sessions. 


\section{Study design}

A randomised controlled trial was selected.

\section{Participants}

As this work comprised a feasibility study intended to determine the efficacy of a newly developed simulation, it was decided that typically developing children should be tested, prior to introduction into a clinical population. Thus children aged 5-7 years (mean 6 years, $\mathrm{SD} \pm 5 \mathrm{~m}$ ), with no physical or cognitive impairment (as determined by their class teacher) were eligible to participate in this feasibility study. An exclusion criterion was prior use of a PWC. Information sheets and consent forms were issued to 56 children ( 2 classes) who attended a local primary school (see figure 1). Issues of anonymity, confidentiality and the right to withdraw from the research were explained in the information sheet. Guardians who agreed that their children could take part in the research were required to sign the consent form and return this to the school for collection by the research team.

Twenty-eight children (13M, 15F) returned consent forms and were randomly assigned to either the intervention (simulation, $\mathrm{n}=14$ ) or control groups (no simulation, $\mathrm{n}=$ 14) by CK. Twenty-six children were right-hand dominant, and 5 had corrected vision. Testing took place on school premises over a three week period in June 2012.

\section{Insert figure 1 about here}

\section{Simulation}

The computer simulation was created using Unity software version 3.4.1, and contained four levels of increasing difficulty that varied in appearance, content and length. In each level children were asked to use a joystick to navigate around a fixed route, remaining 
on the path and avoiding colliding with objects placed at the edges of the path. Level 1 was relatively short and included simple turns, and obstacles. Level 2 guided participants through a number of slalom courses in addition to simple turns. Level 3 included more acute turns, gaps of varying widths, and low gradient ramps. Level 4 included the most acute turns, a variety of gaps, and ramps of varying incline. Collisions with landscape features were marked by a noise and an on-screen counter displayed the event. A second counter recorded completion time, which together with collisions/errors, was used to calculate a total score for every trial. Figure two presents a screen shot of level 1.

\section{Insert figure 2 about here}

The joystick used for the computer game (Ultra Stik 360 Bat Top Joystick) was selected as it was similar in dimensions to that of the PWC used in the study. An interface was created to enable the joystick to be directly connected to a laptop computer (Acer Aspire). The simulation was then projected onto a flat white wall using a data projector (Optoma GT750) in order to create a more immersive training environment for the child. Children were seated comfortably at a table $1.5 \mathrm{~m}$ from the projected image $(0.9 \times 0.6 \mathrm{~m})$ with the joystick positioned centrally.

\section{Outcome Measurements}

A single assessor (ML), blinded to group allocation, assessed the participants wheelchair proficiency pre and post intervention using a previously published functional evaluation rating scale (Hasdai et al., 1998). This 12 item tool was designed to assess a variety of PWC skills in a clinical population and was validated through expert agreement. Participants were rated on a four point scale $(1=$ very good, $2=$ needs improvement, $3=$ tried to perform and $4=$ was not able to perform). Scores could potentially range from 12 to 48 with lower scores indicating better performance. A second assessor (CK) scored $20 \%$ of 
participants at time one, with level of agreement between assessors being determined by the Kappa statistic. Inter-rater agreement was 0.74 which is considered substantial (Landis, \& Koch, 1977). This rating scale comprised the primary outcome measure and was used to assess the effectiveness of the intervention.

Data from each level of the simulation including 'time to completion' (measured in seconds), 'number of collisions/errors' (measured in whole numbers), and 'total score' were also collected. Total score was calculated as $[0.1 /$ (collisions*time to completion) $\left.]^{*} 10,000,000\right]$. These secondary data were collected solely from the intervention group and was used for descriptive analyses.

\section{Procedure}

Following consent, and immediately prior to their pre-study assessment, all participants were given the opportunity to familiarise themselves with the wheelchair (Invacare Mirage) and its joystick controller in an unpowered state. Their proficiency in operating the chair was then assessed.

Children randomised to the intervention group each received training on the computer simulation over eight separate half hour sessions by a single member of the research team (CW). Children were systematically guided through each level during the first 6 training sessions, starting at Level 1. For the final 2 training sessions children were allowed to select their preferred levels to encourage continued engagement with the intervention. Participants were instructed to complete each level as quickly as possible and avoid colliding with obstacles or veering off the pre-determined path. After completion of each trial participants were shown their score on a high score screen, with the dual purpose of providing feedback on their performance and motivating them to improve their score. All training was performed 
over four weeks and participants had at least one rest day between training sessions. The control group received no alternate training during this period.

Following the intervention period all the children from both groups (apart from one absentee male from the control group) were once again assessed on their proficiency in operating the PWC.

\section{Statistical analyses}

Statistical analyses were performed using SPSS v17.0. The Chi-square test was used to compare baseline differences between the intervention and control conditions in terms of group characteristics. ANOVA, with planned comparisons, was used to explore within and between groups differences. Correlates of pre-test PWC proficiency were assessed using multiple regression analysis. Spearman's rank order correlation coefficients were used to examine the relationship between gender, vision and pre-test PWC proficiency with change in PWC proficiency due to the non-parametric nature of some of the data. Secondary data from the simulation were also analysed by the Spearman's rank order correlation coefficient due to their skewed distribution.

\section{Results}

\section{Baseline comparability}

Chi-square tests were conducted to check that the intervention and control groups were well matched. No significant differences were found in relation to gender $\left(\chi^{2}=1.29, p=\right.$ $0.256)$, handedness $\left(\chi^{2}=2.15, p=0.142\right)$ or vision $\left(\chi^{2}=0.24, p=0.622\right)$. An independent samples t-test also showed no statistically significant differences between the groups in regard to age $[\mathrm{t}=-0.981, \mathrm{df}=25, p=0.336$; two tailed $]$. 


\section{Descriptive results from the simulation}

All 14 children in the simulation group attended all 8 scheduled intervention sessions, although one child requested reduced game time from session 4 onwards. Descriptive statistics for the intervention group (see table 1) showed that participants played more of level one than any other level. Many of the children felt that this was the easiest of the levels with some using 'short cuts' to decrease their time score. Table 1 shows that the least played level was level 4 which was also where the children made most errors. The increased difficulty of this final level, acute turns and successive ramps, resulted in a less enjoyable experience for the children, with some expressing frustration and giving up at this point.

Insert table 1 about here

\section{Test of between and within subjects effects}

A 2x2 mixed ANOVA exploring the effects of time (pre and post) and the intervention on functional assessment scores showed a main effect of time $[F(1,25)=9.632$, $p=0.005$, partial $\left.\eta^{2} 0.278\right]$ but no effect of the intervention $[F(1,25)=0.304, p=0.586$, partial $\left.\eta^{2} 0.012\right]$. There was no statistically significant interaction between intervention and time. Two one-way repeated measures ANOVA, were used to explore the main effect of time, and showed a statistically significant effect of time for participants in the intervention $[F(1,12)=6.701, p=0.022]$ but not the control condition $[F(1,12)=3.459, p=0.088]$. The mean scores for the functional assessment scale showed that the intervention group improved from $\mathrm{M}_{1}=15.64(\mathrm{SD} 2.68)$ to $\mathrm{M}_{2}=14.21$ (SD 1.72). The control group's score also improved from $\mathrm{M}_{1}=15.92(\mathrm{SD} 2.25)$ to $\mathrm{M}_{2}=14.69$ (SD 1.55), however, this was not statistically significant. 


\section{Predictors of pre-test PWC proficiency scores}

The variables Gender, Vision (corrected and uncorrected) and Handedness were entered into a multiple regression model to determine if any were predictive of pre-test functional assessment scores. The overall model was statistically significant $[\mathrm{F}(3,24)=$ $5.468, p=0.005$ ], however only gender emerged as a significant predictor (see table 2). Males performed better than females on both pre and post-test PWC assessment $\left(\mathrm{M}_{1 \mathrm{Male}}=\right.$ 14.31, $\mathrm{SD}=1.44 ; \mathrm{M}_{1 \mathrm{Female}}=17.00, \mathrm{SD}=2.39 ; \mathrm{M}_{2 \text { Male }}=13.33, \mathrm{SD}=0.98 ; \mathrm{M}_{2 \mathrm{Female}}=15.33$, SD 1.50). Both males and females improved on the PWC task between times 1 and 2.

Insert table 2 about here

\section{Correlates of change in PWC proficiency}

Non-parametric bivariate correlations were carried out to examine the relationship between the change in PWC proficiency and two variables: (1) gender, as it was identified as the single significant predictor of pre-test PWC score and (2) pre-test PWC proficiency, as overall driving ability may be related to change in PWC proficiency. This analysis was completed for the intervention group only, due to the lack of change observed in the control group (as demonstrated in the ANOVA). A significant negative correlation was observed between change in PWC proficiency and pre-test PWC score $\left(\mathrm{r}_{\mathrm{s}}=-0.622, p=0.018\right)$. No statistically significant relationship was identified between change in PWC proficiency and gender.

\section{PWC proficiency and simulation scores}

Four Spearman's correlations were conducted to explore the associations between the PWC proficiency assessment and simulation scores. This nonparametric test was used due to 
the relatively small number of participants in the intervention group $(n=14)$ and to account for the increased risk of a Type I error caused by performing multiple tests. Table 3 shows a moderate, negative association between the functional assessment score following the intervention and scores on levels 3 and 4 of the simulation.

Insert table 3 about here

\section{Discussion}

This study demonstrates that a brief amount of time ( 4 hours) spent on a simulated PWC task can improve learning in the use of a PWC in typically developing children. It should be noted that the control group also improved in terms of their PWC operation $($ control mean pre - post difference $=1.23$; intervention mean pre - post difference $=1.43)$ although this difference was not statistically significant. Participants in the intervention group appeared capable of transferring the skills developed during the computer simulation joystick task to their performance in the real-world environment with a PWC. This suggests that the simulation could be effective in reducing training times for children who require powered mobility. Children with cerebral palsy and progressive muscular dystrophy have previously been shown to benefit from 12 hours of simulated maze training with the resultant recommendation that simulators be used in the absence of, and in preparation for, PWC use (Hasdai et al., 1998). Children in the current study were not motor impaired and required less training time to produce a learning effect.

Gender was shown to be predictive of baseline functional assessment score. During assessment it was noted that some of the girls were hesitant in performing the specified tasks. This may have been due to the lack of familiarity with operating a PWC or may have 
reflected a more cautious nature. In contrast, some of the boys were rash in controlling the chair, treating it as if it were a toy. Boys outperformed girls on both the pre and post PWC proficiency assessment. Being male has been shown to be predictive of manual wheelchair skills in adults with spinal cord injury (Wan \& Chiou, 2006; Hosseini, Oyster, Kirby, Harrington, \& Boninger, 2012). However, in spite of the baseline gender differences observed in PWC proficiency, gender was not significantly associated with change scores in the intervention group. Our findings suggest that girls may require additional support to reach the same level of PWC operation as their male contemporaries.

Findings showed two negative correlations between game scores on levels 3 and 4 and the PWC proficiency post- scores. As scores on levels 3 and 4 increased, those on the assessment decreased, suggesting improvement in PWC proficiency. This suggests that how children perform on these levels may be more closely associated with improved performance on the PWC task. These levels were the least played as shown in table 1. This may indicate that these were perceived as being less fun or more difficult for the children. While earlier levels were played more, perhaps reflecting the children's enjoyment of them, the later levels required greater care and control to successfully complete. This control is necessary for the safe operation of a PWC, however, children's enjoyment of the simulation is crucial to its uptake. One of the main reasons children cite for playing video games is to gain a sense of achievement (Wan \& Chiou, 2006). If children feel a lack of achievement they are likely to stop using the simulation in the absence of external motivation.

The motivation of participants to succeed at either the training or the PWC functional assessment was not ascertained, however it may conceivably be lower than that of children 
with either congenital or acquired disabilities. It might therefore be expected that the latter group would exhibit a greater desire to engage with a PWC simulation than those with no physical limitations. Interestingly, children who are impaired from birth view assistive devices as a means to improve their physical functioning, while those with acquired disabilities may view them as a marker of loss (Scherer, 2000).

Wheelchair services in the UK have been extensively reviewed over the past decade, with the goal of providing a more responsive and client-centred service (Magnuson, 1996; Jones et al., 2003; Bottos et al., 2001). Standards for wheelchair provision are available (Health Care Standards for Wheelchair Services, 2005), but interestingly do not detail client training required with a prescribed device. Furthermore, although the UK Highway Code details rules for users of powered wheelchairs and mobility scooters (The Highway Code 2012), these are not subject to mandatory testing. Given that a recent study from the US reported that almost $70 \%$ of mobility-aid related injuries in children aged less than 19 years occurred while patients were using wheelchairs (Barnard. Melson, Xiang, \& McKenzie, 2010), it is important to consider the safety of both users and the general public when providing and training a child in the use of a PWC.

\section{Limitations}

This study sought to explore complex motor learning in young children. Whilst all of the children in the intervention group were able to engage with the simulator some found this more difficult than others. This may reflect the potential difficulties in using a simulator task with children who have cognitive impairments. Children with moderate to severe learning disabilities are considered for powered mobility, however such decisions are always specific 
to individual child and family circumstances, and recommendations regarding supervision or the provision of additional assistant controls may be made by the rehabilitation team. The suitability of a simulator task for children with cognitive impairments has yet to be determined. This feasibility study would have benefitted from larger participant numbers however, given the experimental nature of the work, and resource constraints, it was not possible to include more children. Characteristics of the sample may thus have influenced our findings as gender was seen to be an important determinant of PWC operation. Whilst there were no statistically significant differences between the groups in relation to gender, more boys were allocated to the intervention $(n=8)$ group than the control $(n=5)$ group. As males were shown to outperform females on the PWC proficiency assessment this imbalance may have affected our results. Future research should be conducted with a larger sample. Finally, a ceiling effect was apparent in the baseline wheelchair proficiency scores which may have resulted in small, yet significant improvements in wheelchair proficiency remaining undetected.

\section{Conclusions}

This research represents an initial step in determining the usefulness of the simulation in teaching children to operate a PWC. It is our intention to further refine this to include elements of levels 3 and 4 in earlier levels and then test the intervention in a population of childhood wheelchair users. Pending successful results from a more clinical based intervention, one might hope that this type of technology could ultimately offer a novel and low cost way of accelerating learning and improving skill acquisition in children and young people who use PWCs. 


\section{Acknowledgements}

Mr. Michael McQuitty, Invacare, Northern Ireland; Staff and pupils of St Joseph's Primary School, Belfast, N Ireland; Mr Tom Southworth, software engineer.

Funding received: This research was supported by a grant from the Trauma and Rehabilitation Translational Research Group of the Research and Development Office, Northern Ireland. The funders played no part in the design, data collection, analysis, preparation or decision to publish the manuscript.

Conflicts of interest: The authors report no conflicts of interest.

\section{References}

Armstrong, W., Borg, J., Krizack, M., Lindsley, A., Mines, K., Pearlman, J., Reisinger, K., \& Sheldon, S. (2008). Guidelines on the provision of manual wheelchairs in less resourced settings. World Health Organization, WHO Press.

Barnard, A.M., Melson, N.G., Xiang, H., \& McKenzie, L.B. (2010). Pediatric mobility aidrelated injuries treated in US emergency departments from 1991-2008. Pediatrics, $125,1200-1207$.

Bottos, M., Bolcati, C., Sciuto, L., Ruggeri, C., \& Feliciangeli, A. (2001). Powered wheelchairs and independence in young children with tetraplegia. Developmental Medicine \& Child Neurology, 43, 769-777.

Brooks, N.A. (1991). Users' responses to assistive devices for physical disability. Social Science \& Medicine, 32, 1417-1424. 
Crothers, I.R., Linden, M.A., \& Kennedy, N. (2007). Attitudes of children towards peers with acquired brain injury (ABI). Brain Injury, 21(1), 47-52.

Davies M. (2006). School when you are on wheels. Young wheelchair users in Wales: A snapshot of challenges and experiences in education. Report by the Contact a Family Wales charitable body.

Department of Health Social Services and Public Safety Northern Ireland (DHSSPSNI) (2008). Proposals for the reform of the Northern Ireland wheelchair service. August 2008. Accessed on-line $30^{\text {th }}$ July 2012 at http://www.dhsspsni.gov.uk/proposals for the reform of the northern ireland w heelchair_service pdf $3 \mathrm{mb}$. .pdf

Fernandes, T. (2006). Independent mobility for children with disabilities. International Journal of Therapy and Rehabilitation, 13(7), 329-333.

Hasdai, A., Jesse, A.S., \& Weiss, P.L. (1998). Use of a computer simulator for training children with disabilities in the operation of a powered wheelchair. American Journal of Occupational Therapy, 52(3), 215-220.

Health Care Standards for Wheelchair Services Under The National Health Service, Version 5. (2005). Available on-line at http://www.wheelchairmanagers.nhs.uk/servicestandards.pdf, accessed 30 July 2012.

Home, A.M., \& Ham, R. (2003). Provision of powered mobility equipment to young children: the Whiz Kidz experience. International Journal of Therapy and Rehabilitation, 10(11), 511-518. 
Hosseini, S.M., Oyster, M.L., Kirby, R.L., Harrington, A.L., \& Boninger, M.L., Manual wheelchair skills capacity predicts quality of life and community integration in persons with spinal cord injury, Archives of Physical Medicine and Rehabilitation, doi: 10.1016/j.apmr.2012.05.021.

Huang, I-C, Sugden, D., \& Beveridge, S. (2009). Assistive devices and cerebral palsy: the use of assistive devices at school by children with cerebral palsy. Child Care Health and Development, 35(5), 698-708.

Inman, D.P., Loge, K., Cram, A. \& Peterson, M. (2011). Learning to drive a wheelchair in virtual reality. Journal of Special Education Technology, 26(3), 21-34.

Jones, M.A., McEwen, I.R., Hansen, L. (2003). Use of power mobility for a young child with spinal muscular atrophy. Physical Therapy, 83, 253-262.

Kilkens, O.J., Dallmeijer, A.J., Angenot, E., Twisk, J.W., Post, M.W., \& van der Woude, L.H. (2005). Subject and injury-related factors influencing the course of manual wheelchair skill performance during initial inpatient rehabilitation of persons with spinal cord injury. Archives of Physical Medicine and Rehabilitation, 86, 21192125.

Landis, J.R., \& Koch, G.G. (1977). The measurement of observer agreement for categorical data. Biometrics, 33(1), 159-174.

Linden, M.A., \& McClure, J. (2012). The causal attributions of nursing students towards adolescent survivors of brain injury. Nursing Research, 61, 58-65.

Magnuson, S. (1996). Powered Mobility for Young Children with Physical Disabilities. Physical \& Occupational Therapy in Pediatrics, 15(3), 71-79. 
Palisano, R.J., Tieman, B.L, Walter, S.D., Bartlett, D.J., Rosenbaum, P.L., Russell, D., Hanna, S.E. (2003). Effect of environmental setting on mobility methods of children with cerebral palsy. Developmental Medicine \& Child Neurology, 45, 11320.

Sapey, B., Stewart, J., \& Donaldson, G. (2004). The social implications of increases in wheelchair use. Department of Applied Social Science, Lancaster University.

Scherer, M.J. (2000) Living in the State of Stuck: How Technology Impacts The Lives of People with Disabilities. Brookline Books, Cambridge, MA, USA.

Sedgwick, M., Frank, A., Kemp, P., \& Gage, P. (2005). Improving services for wheelchair users and carers. Good practice guide: learning from the Wheelchair Services Collaborative. London: National Health Service, Department of Health.

Sharma, N., \& Morrison, J. (2007). Don't push me around! Disabled children's experiences of wheelchair services in the UK. Accessed on-line $30^{\text {th }}$ July 2012 at http://www.whizz-kidz.org.uk/wpcontent/uploads/2010/02/dont_push_me_around.pdf

Steinmetz, E. (2004). Americans with Disabilities: 2002; Current Population Reports, P70107, U.S. Census Bureau, Washington, DC. Accessed on-line $1^{\text {st }}$ August 2012 at http://ww/w.census.gov/hhes/www/disability/sipp/disab02/awd02.html

The Highway Code: Rules for users of powered wheelchairs and mobility scooters available at http://www.direct.gov.uk/en/travelandtransport/highwaycode/dg 069852, accessed 30 July 2012 
van Merriënboer, J.J.G., Clark, R.E., de Croock, M.B.M. (2002). Blueprints for complex learning: The 4C/ID-Model. Educational Technology Research and Development, 50(2), 39-64.

van Merriënboer, J.J.G., Jelsma, O., \& Paas, F.G.W.C. (1992). Training for reflective expertise: A four-component instructional design model for training complex cognitive skills. Educational Technology Research and Development, 40(2), 23-43.

Wan, C.S., \& Chiou, W.B. (2006). Why Are Adolescents Addicted to Online Gaming? An Interview Study in Taiwan. Cyberpsychology, Behavior, and Social Networking, $9(6), 762-766$.

Whizz-Kidz (2011). All Party Parliamentary Group for Paediatric Wheelchair Reform. My wheelchair is my shoes: making the case for wheelchair reform. Accessed on-line $30^{\text {th }}$ July 2012 at http://www.whizz-kidz.org.uk/wp-

content/uploads/2011/06/APPG-Report-My-Wheelchair-is-My-Shoes-Final2.pdf 
Figure 1: Flowchart of study recruitment

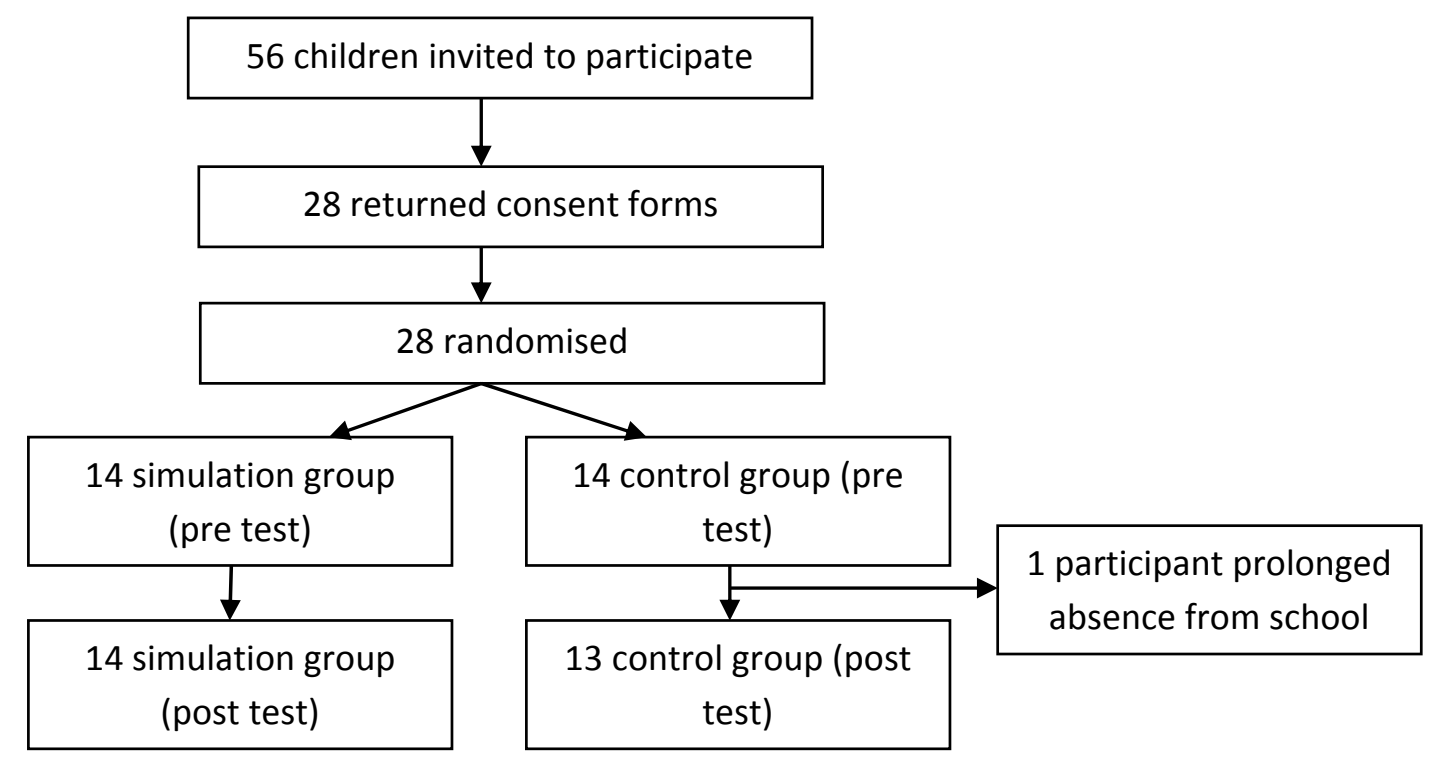




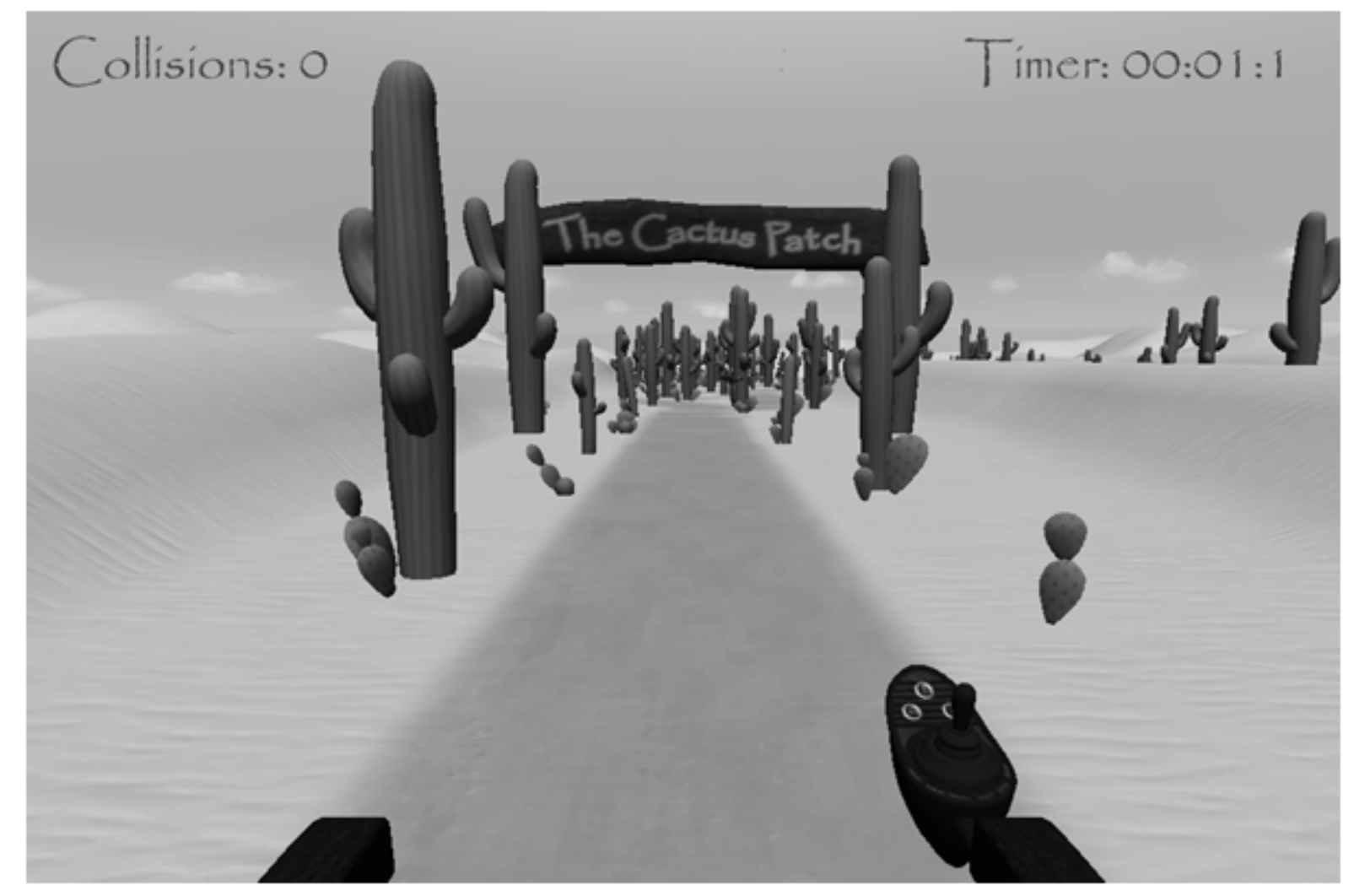

Figure 2: Screen shot of simulation level 1 'The Cactus Patch'. 
Table 1: Time and sessions played with errors and total score for each simulation level.

\begin{tabular}{|c|c|c|c|c|}
\hline & $\begin{array}{c}\text { Sessions played * } \\
\text { (Min-Max, Mean, SD) }\end{array}$ & $\begin{array}{c}\text { Time (seconds) } \\
\text { (Min-Max, Mean, SD) }\end{array}$ & $\begin{array}{c}\text { Errors } \\
\text { (Min-Max, Mean, SD) }\end{array}$ & $\begin{array}{c}\text { Simulation Score } \\
\text { (Min-Max, Mean, SD) }\end{array}$ \\
\hline Level one: & $\begin{array}{c}10-24, \\
14.71,4.32 \\
\end{array}$ & $\begin{array}{c}59-150 \\
98.90,27.12 \\
\end{array}$ & $\begin{array}{c}0-6 \\
2.96,2.03 \\
\end{array}$ & $\begin{array}{c}4328-15226, \\
8779.65,3604.72 \\
\end{array}$ \\
\hline Level two: & $\begin{array}{c}\text { 5-20, } \\
10.79,3.19 \\
\end{array}$ & $\begin{array}{c}162-276 \\
234.62,34.96\end{array}$ & $\begin{array}{c}0-15 \\
6.24,3.72 \\
\end{array}$ & $\begin{array}{c}528-4643, \\
2145.96,1178.08\end{array}$ \\
\hline Level three: & $\begin{array}{c}2-18 \\
8.57,3.59\end{array}$ & $\begin{array}{c}199-462 \\
248.96,68.20\end{array}$ & $\begin{array}{c}0-7 \\
2.65,1.96\end{array}$ & $\begin{array}{c}\text { 479-4955, } \\
2998.05,1227.04\end{array}$ \\
\hline Level four: & $\begin{array}{c}2-10 \\
5.43,2.21\end{array}$ & $\begin{array}{c}143-251 \\
196.94,31.62\end{array}$ & $\begin{array}{c}0-20 \\
7.02,5.28\end{array}$ & $\begin{array}{c}940-5708 \\
2386.12,1425.82\end{array}$ \\
\hline
\end{tabular}

*Participants $\mathrm{n}=14$ 
Table 2: Regression model of demographic variables predictive of pre test functional assessment

\begin{tabular}{lllc}
\hline Variables & $\boldsymbol{B}$ & $\boldsymbol{p}$ & Model Adjusted $\boldsymbol{R}^{\mathbf{2}} \boldsymbol{p} \boldsymbol{p}$ \\
\hline & & & \\
Pre-test scores & & & $0.332 ; \boldsymbol{p}=0.005$ \\
Vision (corrected, uncorrected) & -0.291 & 0.095 & \\
Handedness & -0.117 & 0.471 & \\
Gender & $\mathbf{0 . 4 7 7}$ & $\mathbf{0 . 0 0 8}$ & \\
& & & \\
\hline
\end{tabular}


EFFICACY OF A POWERED WHEELCHAIR SIMULATOR 26

Table 3: Spearman's correlations between post functional assessment and simulation scores.

\begin{tabular}{|l|c|c|}
\hline Simulation levels & Correlation coefficient ${ }^{*}$ & Significance (2-tailed) \\
\hline Level one: & -0.219 & 0.452 \\
\hline Level two: & -0.332 & 0.247 \\
\hline Level three: & -0.594 & $\mathbf{0 . 0 2 5}$ \\
\hline Level four: & -0.571 & $\mathbf{0 . 0 3 3}$ \\
\hline
\end{tabular}

* Participants $n=14$ 